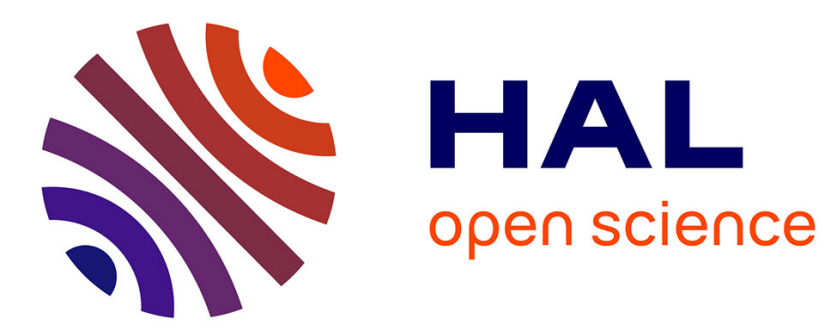

\title{
Mite infestation during development alters the in-hive behaviour of adult honeybees
}

Desiderato Annoscia, Fabio del Piccolo, Francesca Covre, Francesco Nazzi

\section{To cite this version:}

Desiderato Annoscia, Fabio del Piccolo, Francesca Covre, Francesco Nazzi. Mite infestation during development alters the in-hive behaviour of adult honeybees. Apidologie, 2015, 46 (3), pp.306-314. 10.1007/s13592-014-0323-0 . hal-01284445

\section{HAL Id: hal-01284445 \\ https://hal.science/hal-01284445}

Submitted on 7 Mar 2016

HAL is a multi-disciplinary open access archive for the deposit and dissemination of scientific research documents, whether they are published or not. The documents may come from teaching and research institutions in France or abroad, or from public or private research centers.
L'archive ouverte pluridisciplinaire $\mathbf{H A L}$, est destinée au dépôt et à la diffusion de documents scientifiques de niveau recherche, publiés ou non, émanant des établissements d'enseignement et de recherche français ou étrangers, des laboratoires publics ou privés. 


\title{
Mite infestation during development alters the in-hive behaviour of adult honeybees
}

\author{
Desiderato Annoscia, Fabio Del Piccolo, Francesca Covre, Francesco Nazzi
}

Dipartimento di Scienze Agrarie e Ambientali, Università degli Studi di Udine, Udine, Italy

Received 21 March 2014 - Revised 18 July 2014 - Accepted 29 September 2014

\begin{abstract}
Honeybee colonies (Apis mellifera) host a number of parasites, among which the mite Varroa destructor has been implicated in colony losses recorded around the world in recent years. Although many studies have been carried out on the direct and indirect damage caused by the mite to its host, the possible influence of mite infestation on the in-hive behaviour of honeybees has received little attention so far; moreover, to our knowledge, no behavioural study has been performed on adult bees infested during the pupal stage, which is when the mite causes most of its detrimental effects. In order to assess any possible consequence of infestation on the in-hive behaviour of honeybees, we carried out detailed observations on adult bees artificially infested during the pupal stage. We recorded a higher proportion of inactive bees among the infested ones; moreover, we observed that infested bees are less involved in tending larvae and dealing with hive duties compared to their uninfested mates. These results allow to draw some hypotheses which could be tested using the infestation method presented here.
\end{abstract}

\section{Apis mellifera / Varroa destructor / deformed wing virus / behaviour / in-hive activity}

\section{INTRODUCTION}

Parasitism is likely the most common lifestyle in the animal kingdom (Price 1980). Generally, parasites show a high degree of adaptability to their host, but a number of cases are known where the parasite actually changes the behaviour of the host rather than adjusting to it (Libersat et al. 2009; Poulin 2010). In general, parasites manipulate the behaviour of the host in order to improve their reproductive capacity or the ability to spread and survive (Thomas et al. 2005).

Honeybee colonies (Apis mellifera L.) host a large number of parasites, among which the mite Varroa destructor Anderson and Trueman is the most harmful for its potential effects on the very survival of the colony (Rosenkranz et al. 2010;

Corresponding author: D. Annoscia, desiderato.annoscia@uniud.it; F. Nazzi, francesco.nazzi@uniud.it Manuscript editor: Peter Rosenkranz
Sammataro et al. 2000). In particular, it is now widely accepted that the decline of honeybee colonies observed on a large scale in recent years is mainly related to the detrimental effects exerted by the mite (Le Conte et al. 2010; Neumann and Carreck 2010). At the individual level, $V$. destructor can reduce the lifespan of infested honeybees and determine a wealth of physiological alterations, including reduced weight and water content of emerging honeybees (Annoscia et al. 2012; Bowen-Walker and Gunn 2001; Yang and CoxFoster 2007). Additional physiological changes induced by the parasite regard metabolism, vitellogenin titre and the proportion of normal haemocytes (Amdam et al. 2004; McDonnell et al. 2013; Richards et al. 2011; van Dooremalen et al. 2013).

Furthermore, the mite can influence honeybee behaviour by promoting an accelerated maturation leading to a precocious onset of the foraging activity (Downey et al. 2000), which is altered in terms of flight duration and orientation ability (Kralj and Fuchs 2006; Kralj et al. 2007). 
Most of the early studies correlated the adverse effects of mite infestation to the direct action of the parasite, including the crippled wings shown by bees emerging from infested cells (De Jong et al. 1982). However, it is now clear that $V$. destructor can trigger the replication of the deformed wing virus (DWV) (Nazzi et al. 2012) which is normally present in bees at non-lethal levels as demonstrated by several studies showing that DWV is widespread in Europe with a prevalence approaching, in Summer, $100 \%$ (Dainat et al. 2012; de Miranda and Genersch 2010; Nazzi et al. 2012). Actually, extremely high titres of DWV, resulting from mite infestation, are the true responsible for the wing deformities noted in infested bees (Bowen-Walker et al. 1999; Chen et al. 2005; Yue and Genersch 2005). However, deformed-wing bees survive for only 1-2 days (Yang and Cox-Foster 2007), whereas normalwinged bees emerging from mite-infested brood cells show DWV infection levels that are significantly higher than those recorded in uninfested bees (Nazzi et al. 2012; Yang and Cox-Foster 2005), confirming the inescapable interaction between the mite and virus.

For all these reasons, apart from the practical difficulties in dissecting the possible effects caused by the Varroa mite and DWV, under a practical point of view, it is the study of the combined action of the mite and the virus that represents the most relevant problem to be addressed.

Recently, the effect of mite infestation on the interactions between bees, within the hive, has been investigated (McDonnell et al. 2013); however, to date, nobody has studied the possible effects of mite infestation, suffered during the pupal stage, on the behaviour of bees in a controlled experiment. Therefore, we carried out detailed observations on the behaviour of adult bees artificially infested during the pupal stage to assess any possible consequence of infestation and the resulting viral proliferation at the behavioural level.

\section{MATERIAL AND METHODS}

The biological material (honeybee larvae and $V$. destructor adult females) was collected in the experimental apiary of the Department of Agricultural and Environmental Sciences of the University of Udine (Italy). Previous studies indicated that local colonies are hybrids between A. mellifera ligustica Spinola and A. mellifera carnica Pollmann (Comparini and Biasiolo 1991; Nazzi 1992).

Previous studies indicated that DWV is widespread in this area as well as in the rest of Europe (de Miranda and Genersch 2010; Francis et al. 2013; Nazzi et al. 2012); moreover, we recently showed that, in our region, in Summer, DWV prevalence approaches $100 \%$ so we can confidently assume that all bees considered in this study were DWV-infected and that mite infestation caused a higher load of viral particles as compared to that in uninfested bees (Nazzi et al. 2012). As far as other bee viruses are concerned, previous field data about prevalence and seasonality of common bee viruses in this area (Nazzi et al. 2012) suggest that their influence was likely negligible. As regards to the possible experimental confirmation of the above mentioned data for the bees used in the experiments, it is worth mentioning that there are no methods for testing viral infection in alive bees such as those used for our observations; on the other hand, a possible post-mortem analyses, if possible, would not be relevant since DWV copy number tends to change along the bee's life (de Miranda et al. 2013).

Bee larvae from brood cells capped in the preceding $15 \mathrm{~h}$ and mites from the same cells were collected as described previously (Nazzi et al. 2012). The individuals were collected randomly from several colonies of the experimental apiary both within the same replication and between the different replications. Larvae were transferred into gelatine capsules (Agar Scientific Ltd.,

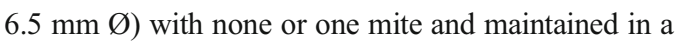
climatic chamber $\left(34{ }^{\circ} \mathrm{C}, 75 \%\right.$ relative humidity $(\mathrm{RH})$, dark) for 12 days (Nazzi and Milani 1994). At the eclosion, newly emerged adult bees were separated from the infesting mite and transferred into plastic cages $(185 \times 105 \times 85 \mathrm{~mm})$ maintained in a climatic chamber $\left(34{ }^{\circ} \mathrm{C}, 75 \% \mathrm{RH}\right.$, dark) with sugar candy (Apifonda ${ }^{\circledR}$ ) and water ad libitum. After 2 days, the infested and uninfested bees were marked with a queen marker kit, consisting of coloured-numbered tags ( $2 \mathrm{~mm} \varnothing)$ applied on the thorax with a resin-type glue, and transferred into an observation hive housing a single nest comb and a super comb (Dadant-Blatt size) separated by a queen 
excluder. Glass walls on both sides, normally obscured with wooden panels, allowed the direct observation of bees' activity; a hole at the top of the box allowed supplementary nutrition if needed; a short tunnel allowed the bees to walk outside the hive, which was allocated indoor to facilitate periodical observations. The observation hive hosted a small colony (about 4,500 adult bees) established in the same year of the biological experiments.

The marked bees were observed, two times a day, every 1-2 days, for $15 \mathrm{~min}$, for 5 weeks. During this time interval, the behaviour of all visible marked bees was classified as follows:

1. In brood cell, if the bee was observed inside a cell containing a bee larva or an egg

2. In store cell, if the bee was observed inside a cell containing honey or pollen

3. Ventilation, if the bee was observed fanning the wings while keeping still to circulate the air within the hive

4. Trophallaxis, if the bee was observed with the proboscis in touch with that of another bee, supposing that they were exchanging food

5. Dance, if the bee was observed while doing the round or the waggle dance to indicate the location of a food source

6. With pollen, if the bee was carrying pollen in the pollen basket

7. In movement, if the bee was moving on the comb without carrying out any of the above mentioned activities

8. Still, if the bee was resting and not performing any of the activities mentioned above

At the end of the experiment, the bees' behaviour was summarized into the following categories:

- Tending larvae (TL), activities related to the care of the larvae in brood cells (i.e. category 1)

- Hive duties (HD), activities related to colony maintenance, including ventilation and trophallaxis (i.e. categories 3-4)

- Food collection (FC), activities related to the collection of food (i.e. categories 5-6)

- Other (O), all activities other than those mentioned above

The experiment, from the artificial infestation to the in-hive observation, was repeated four times; in total, the behaviour of 57 uninfested and 56 infested bees was studied in the observation hive (Table I).

The acceptance rate of uninfested and infested bees was analysed using the Mantel-Haenszel test. Differences in the lifespan of uninfested and infested bees were tested with the non-parametric MannWhitney test. The proportion of uninfested and infested bees that appeared inactive or performing different activities during the experiment was compared with a paired $t$ test after angular transformation of data.

\section{RESULTS}

\subsection{Acceptance rate of bees used in the experiment}

Overall, about half of the bees introduced into the experimental hive were observed at least once (34 out 57 uninfested bees corresponding to $59.6 \%$ and 32 out 56 infested bees corresponding to $57.1 \%$ ); the difference between groups was not statistically significant (Mantel-Haenszel test, $P=0.317)$.

\subsection{Lifespan of uninfested and infested bees}

Uninfested bees were observed for a maximum time of 31 days during the experiment, whereas infested bees were observed at most for 23 days, although a high variability among replicates was observed (Table II). The difference between groups was significant (Mann-Whitney $U$ test, $\left.U=0, n_{1}=4, n_{2}=4, P=0.01\right)$.

Table I. Number of uninfested and infested bees introduced in the observation hive in each replication.

Number of bees introduced to the observation hive

\begin{tabular}{lll}
\cline { 2 - 3 } Replication & Uninfested & Infested \\
\hline 1 & 9 & 9 \\
2 & 16 & 14 \\
3 & 13 & 14 \\
4 & 19 & 19 \\
Total & 57 & 56 \\
\hline
\end{tabular}


Table II. Estimated maximum survival time (days from the introduction into the observation hive) for uninfested and infested bees in each replication.

\begin{tabular}{lll}
\hline & \multicolumn{2}{l}{$\begin{array}{l}\text { Estimated maximum survival time } \\
\text { (days) }\end{array}$} \\
\cline { 2 - 3 } Replication & Uninfested & Infested \\
\hline 1 & 31 & 8 \\
2 & 27 & 23 \\
3 & 29 & 11 \\
4 & 24 & 20 \\
\hline
\end{tabular}

\subsection{Proportion of inactive bees}

In general, the proportion of inactive bees was very high in both groups for all bee ages (Figure 1).

In uninfested bees, the highest proportion of inactive individuals was observed during the first week of life and declined until the third week, for rising again later, whereas in the infested bees, this figure was always higher resulting in a significant difference between the two groups (paired $t$ test, $t=3.1, \mathrm{df}=3, P=0.03)$.

\subsection{Activities carried out by uninfested and infested bees}

In total, 10, 10, 8 and 3 bees were observed performing the activities described above during the first, second, third and fourth week of life respectively.

The proportion of uninfested bees tending larvae (TL) increased up to second week; later, during the third week of life, a peak in the in-hive activities, such as ventilation and trophallaxis (HD), was observed; finally, during the fourth week, only one uninfested bee was observed dancing on the combs, thus allowing no conclusions on the food collection (FC) activity (Figure 2a).

On the other hand, the proportion of infested bees observed tending larvae (TL) and dealing with hive duties (HD) was significantly lower compared to that of uninfested mates (paired $t$ test: tending larvae, $t=1.77, \mathrm{df}=3, P=0.09$; hive duties, $t=4.2, \mathrm{df}=3, P=0.01$; Figure $2 \mathrm{~b}$ ). No infested bees were seen performing the activities related to food collection (FC).

\section{DISCUSSION AND CONCLUSIONS}

The number of bees observed at least once out of the total number of specimens used in the experiments provides a rough estimate of the acceptance rate of the bees introduced into the observation hive. The fact that more than half of the bees introduced into the observation hive were accepted, despite the genetic difference with those hosted in the accepting colony, represents a satisfactory achievement and confirms the feasibility of the approach used here. Actually, the

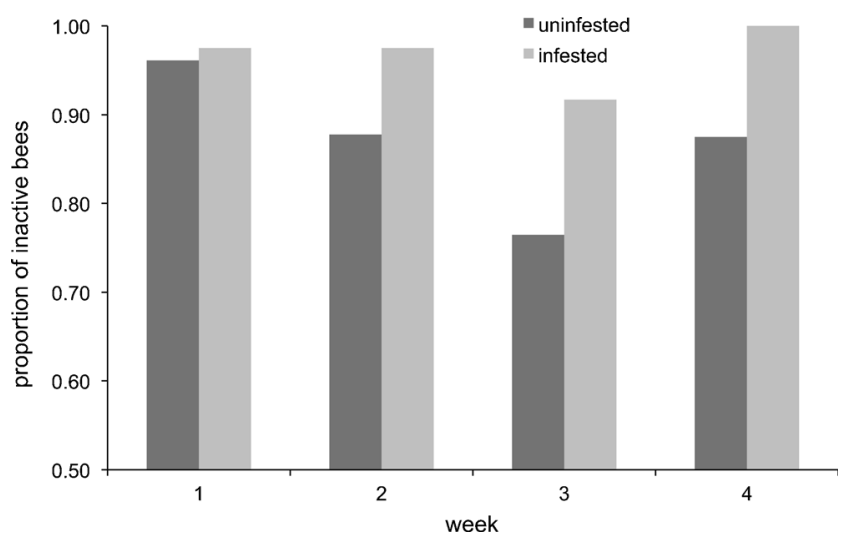

Figure 1. Proportion of uninfested and infested bees that were inactive during the observation according to the age in weeks. 

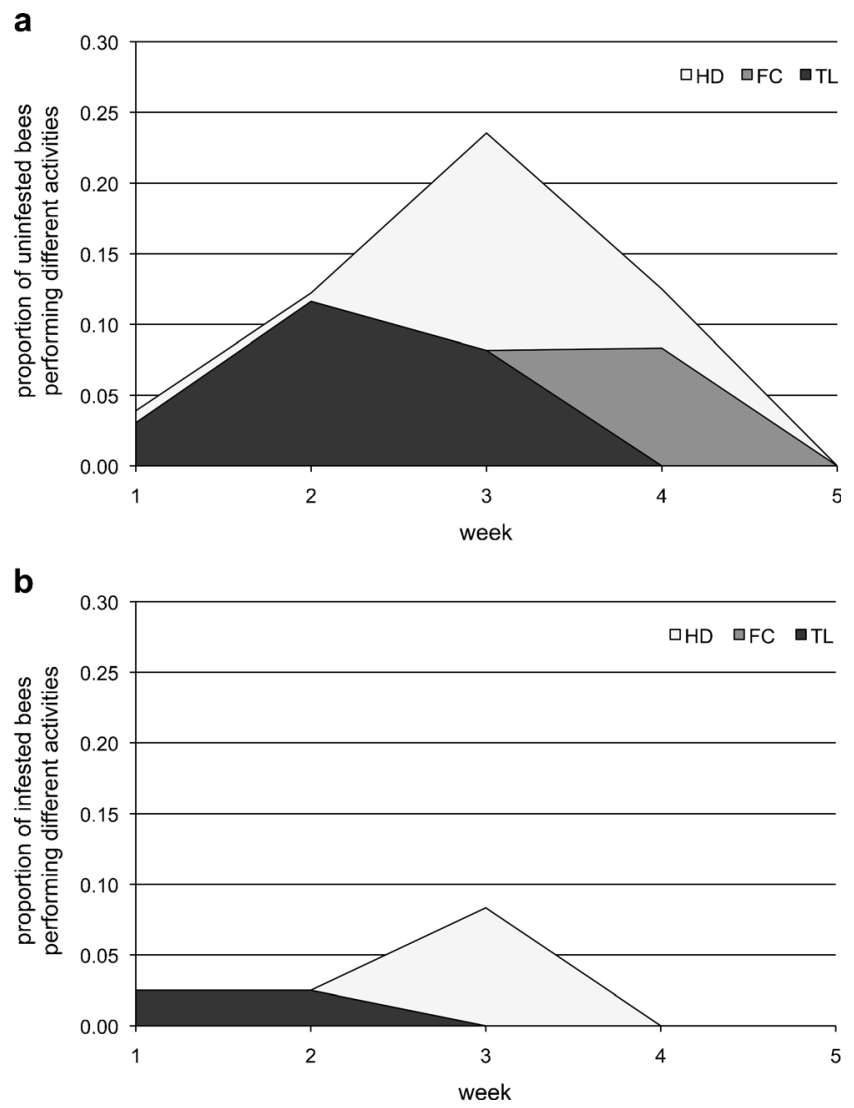

Figure 2. Proportion of uninfested (a) and infested $(\mathbf{b})$ bees performing different activities $(H D=$ hive duties, $F C=$ food collection, $T L=$ tending larvae) according to the age in weeks.

acceptance rate obtained here is higher compared to that reported previously for non-nestmate bees (Downs et al. 2000).

The similar acceptance rate of infested bees compared to that of uninfested ones does not allow to draw any conclusion about a possible effect of the infestation suffered by newly emerged bees during the pupal stage, on the behaviour of house bees towards them. However, an increasing amount of data about the effects of infestation on the composition of cuticular hydrocarbons (Annoscia et al. 2012; McDonnell et al. 2013; Salvy et al. 2001) that are essential for nestmate recognition (Châline et al. 2005; Dani et al. 2005; Page et al. 1991) and some recent evidence about infestation effects on social interaction (McDonnell et al. 2013) suggest that a hostile behaviour towards infested bees would be likely. Actually, the manipulation method used here, where infested bees were reared inside artificial gelatine cells without coming into contact with waxes from an alien hive before being inserted into the hosting colony, is probably the most appropriate for testing the hypothesis that infestation may affect the acceptance of newly emerged bees. Further experiments with larger samples will allow in future to study this interesting aspect under the most suitable conditions.

The experimental protocol adopted here, which included a 12-day infestation period, under lab conditions, followed by a 5-week-long observation period, strongly limits the number of bees that can be used for the observations due to the mortality along the entire process. Nevertheless, we opted for this method since it allowed the use of 
insects in very standardized conditions that, in our opinion, is essential for this kind of studies.

The maximum time, in terms of days after the beginning of the experiment, that the marked bees were observed in the hive provides a rough estimate of the lifespan of bees under the conditions of the experiment. Infested bees were observed for a significant shorter time compared to uninfested bees, confirming previous observation on the reduced survival of such bees, obtained by maintaining bees in cages under lab conditions (Annoscia et al. 2012). Although cage rearing has allowed to collect valuable data about the effects of parasitism on bee survival and other physiological parameters, it drastically deviates from the norm for a social insect such as the honeybee. Actually, in most cases, several expedients were applied to better simulate the hive situation in order to minimize this deviation, including, for example, the use of synthetic queen pheromone to mimic the queen presence, or a minimum number of bees to account for social interactions, or the use of a piece of comb to simulate the presence of a nest (Williams et al. 2013). However, although all this arrangements can be considered as satisfactory when studying, for example, the impact of parasitization on some physiological parameters, a plastic cage containing some dozens of bees can not replace the complex situation found in a hive when studying the behaviour of an insect living in a complex society made of thousands of individuals differing for sex, ages and castes, housed in a nest which is open to the environment. For this reason, the data reported here can be considered a valuable confirmation of previous data obtained under artificial conditions.

The proportion of bees observed while inactive was, in general, rather high. This is surely related to the data collection method and represents only a rough estimate of the bee's activity inside the hive. However, some authors reported long resting times for honeybees (Seeley 1996) that were interpreted as a valuable time for brood food or wax production (Winston 1991) or to save energy in view of an abundant harvest (Anderson 2001).

Interestingly, the proportion of bees observed while inactive was significantly higher for infested bees compared to uninfested ones, suggesting an effect of infestation on the bees' activity.

Uninfested bees performed all the tasks entrusted to them inside the hive (Figure 2a). On the other hand, infested bees were rarely seen tending larvae and performing hive duties. Therefore, it is possible to assume that the mite infestation causes a significant reduction in the activities of bees within the family. This is certainly disadvantageous for the entire colony; in fact, the lack of bees dedicated to the support and sustenance of the nest mates could lead, in a short time, to a dysfunction of the whole hive system with dramatic consequences on colony balance.

In principle, the effects observed here could be related to a generic weakening caused by parasitization, which would prevent the bees from carrying out their normal activities. This is extremely likely in view of the drastic reduction of body mass observed in infested bees compared to healthy ones; in fact, it has been estimated that infested bees can weight $10 \%$ less than uninfested ones (Annoscia et al. 2012; Bowen-Walker and Gunn 2001; Yang and Cox-Foster 2007).

On the other hand, other more specific effects on bee's physiology could be involved. For example, the brood rearing activity may be affected as a consequence of the reduced development of the hypopharyngeal and mandibular glands of the honeybees, which are necessary for larval food production. In fact, it has been shown that mite infestation reduces the size of such glands by an average of $14 \%$, when bees were damaged during pupal stages (Schneider and Drescher 1987).

Other effects related to sensing of chemicals and proper response to them may be involved as well, as suggested by recent data showing that birth weight, which is dramatically affected in case of infestation, is linked to sensory responsiveness to sucrose (Scheiner 2012). Furthermore, an effect of mite parasitization on the cognitive abilities of honeybees has already been demonstrated; in particular, it has been shown that DWV infection, which is boosted by $V$. destructor infestation (Nazzi et al. 2012), leads to specific impairments in sucrose responsiveness and associative olfactory learning, possibly in relation to head infections and related interference with signalling 
cascades underlying learning (Iqbal and Mueller 2007). Similarly, Li et al. (2013) showed that another common honeybee virus (i.e. Israeli acute paralysis virus) replicates in the heads of the infected honeybees, interfering with normal nervous system functions in the brain and affecting their sucrose responsiveness. Moreover, Kakugo virus was detected in the brain (but not in the thorax or abdomen) of aggressive honeybee workers, indicating a close relation between the viral infection and the bees' behaviour (Fujiyuki et al. 2004).

Such effects could disrupt the normal sensitivity and reaction to pheromones including brood and queen mandibular pheromone. Altered sensing or reduced reaction to the brood pheromone produced by the growing larvae crying for food (Le Conte et al. 2001) may affect brood tending. Furthermore, brood pheromone stimulates the hypopharyngeal glands, which trigger pollen feeding and, in turn, maintain a high level of vitellogenin (Johnson 2010); this allows the production of larval food and possibly the suppression of the increase of juvenile hormone (Johnson 2010), preventing the gradual transition to the forager stage.

Similarly, a negative effect on olfactory perception may interfere also with the sensing of the queen mandibular pheromone that suppresses the production of juvenile hormone (Pankiw et al. 1998), which normally increases with age in worker bees, regulating the physiological processes that are associated to division of labour (Robinson 1987); this may influence the timing of the switching to foraging by nurse bees. Furthermore, the queen mandibular pheromone suppresses the title of dopamine in the brain, contributing to decrease the task sensitivity (Johnson 2010).

Moreover, an indirect effect related to the activation of the immune system could be involved as well. In particular, the immune-challenged bees have a reduced ability to associate an odour with a sugar reward, suggesting that the cost of an immune response affects behaviour and memory formation (Mallon et al. 2003). The same was noted in bumblebees, which performed poorly in a memory test when the immune system was stimulated (Riddell and Mallon 2006). Therefore, it is possible that the behaviour of the infested bees could be altered both because of the damage to the nervous system caused by the pathogen itself (Shah et al. 2009) as well as for the engagement of the immune system (Alghamdi et al. 2008; Mallon et al. 2003).

The observed reduction in brood caring activities induced by the mite on its host represents an interesting evidence. In fact, parasites normally tend to change their hosts' behaviour to increase their chances of transmission, spread or survival (Thomas et al. 2005). In this case, we observed that young infested bees spend a reduced time looking after the brood. Since the reproduction of the mite can only take place inside a brood cell that is invaded prior to sealing and the mite is carried to the brood cell to be invaded by a nurse bee, a reduction in brood caring would lead to a net reduction of the chance of cell invasion and thus reproduction of the mite. More studies about the Varroavirus interactions are certainly needed to assess if the results observed here simply reflect a reduced physical fitness caused by the parasitization or may have any possible adaptive value either for the mite or the virus.

In conclusion, the data reported here show a relevant effect of mite infestation on honeybee behaviour and allow to draw some hypotheses on the possible causes, keeping into account that the effects reported here should be considered as the resulting effect of mite infestation and the mite-driven viral replication normally observed in infested bees. Further studies will investigate in detail the mechanism accounting for the observed effects.

Moreover, the results show the feasibility of both the infestation and the rearing method that could well be used to test the above mentioned hypotheses and for a number of other studies.

\section{ACKNOWLEDGMENTS}

This work was funded by the Italian Ministry of Agriculture (MIPAAF): research project "Apenet Ricerca e Monitoraggio in Apicoltura". We gratefully acknowledge Ricarda Scheiner for critically reading the manuscript. 
Une infestation d'acariens au cours du développement modifie le comportement des abeilles adultes à l'intérieur de la ruche

Apis mellifera / Varroa destructor / virus / DWV / comportement / activité intra-ruche

Der Milbenbefall während der Entwicklung verändert das Verhalten von adulten Honigbienen innerhalb des Stockes

Apis mellifera / Varroa destructor / deformed wing virus / Verhalten / Verhalten im Bienenstock

\section{REFERENCES}

Alghamdi, A., Dalton, L., Phillis, A., Rosato, E., Mallon, E.B. (2008) Immune response impairs learning in freeflying bumble-bees. Biol. Lett. 4 (5), 479-481

Amdam, G.V., Hartfelder, K., Norberg, K., Hagen, A., Omholt, S.W. (2004) Altered physiology in worker honey bees (Hymenoptera: Apidae) infested with the mite Varroa destructor (Acari: Varroidae): a factor in colony loss during overwintering? J. Econ. Entomol. 97 (3), 741-747

Anderson, C. (2001) The adaptive value of inactive foragers and the scout-recruit system in honey bee (Apis mellifera ) colonies. Behav. Ecol. 12 (1), 111-119

Annoscia, D., Del Piccolo, F., Nazzi, F. (2012) How does the mite Varroa destructor kill the honeybee Apis mellifera? Alteration of cuticular hydrocarbons and water loss in infested honeybees. J. Insect Physiol. 58(12), 1548-1555

Bowen-Walker, P.L., Gunn, A. (2001) The effect of the ectoparasitic mite, Varroa destructor on adult worker honeybee (Apis mellifera) emergence weights, water, protein, carbohydrate, and lipid levels. Entomol. Exp. Appl. 101 (3), 207-217

Bowen-Walker, P.L., Martin, S.J., Gunn, A. (1999) The transmission of deformed wing virus between honeybees (Apis mellifera L.) by the ectoparasitic mite Varroa jacobsoni Oud. J. Invertebr. Pathol. 73 (1), 101-106

Châline, N., Sandoz, J.C., Martin, S.J., Ratnieks, F.L.W., Jones, G.R. (2005) Learning and discrimination of individual cuticular hydrocarbons by honeybees (Apis mellifera ). Chem. Senses 30 (4), 327-335

Chen, Y.P., Higgins, J.A., Feldlaufer, M.F. (2005) Quantitative real-time reverse transcription-PCR analysis of deformed wing virus infection in the honeybee (Apis mellifera L.). Appl. Environ. Microbiol. 71 (1), 436-441

Comparini, A., Biasiolo, A. (1991) Genetic discrimination of Italian bee, Apis mellifera ligustica versus Carniolan bee, Apis mellifera carnica by allozyme variability analysis. Biochem. Syst. Ecol. 19(3), 189-194
Dainat, B., Evans, J.D., Chen, Y.P., Gauthier, L., Neumann, P. (2012) Dead or alive: deformed wing virus and Varroa destructor reduce the life span of winter honeybees. Appl. Environ. Microbiol. 78(4), 981-987

Dani, F.R., Jones, G.R., Corsi, S., Beard, R., Pradella, D., Turillazzi, S. (2005) Nestmate recognition cues in the honey bee: differential importance of cuticular alkanes and alkenes. Chem. Senses 30 (6), 477-489

De Jong, D., De Jong, P.H., Gonçalves, L.S. (1982) Weight loss and other damage to developing worker honeybees from infestation with Varroa jacobsoni. J. Apic. Res. 21 (3), 165-167

de Miranda, J.R., Genersch, E. (2010) Deformed wing virus. J. Invertebr. Pathol. 103 (Suppl. 1), S48-S61

de Miranda, J.R., Bailey, L., Ball, B.V., Blanchard, P., Budge, G.E., et al. (2013) Standard methods for virus research in Apis mellifera. J. Apic. Res. 52 (4), 1-56

Downey, D.L., Higo, T.T., Winston, M.L. (2000) Single and dual parasitic mite infestations on the honey bee, Apis mellifera L. Insectes Soc. 47 (2), 171-176

Downs, S.G., Ratnieks, F.L.W., Jefferies, S.L., Rigby, H.E. (2000) The role of floral oils in the nestmate recognition system of honey bees (Apis mellifera L.). Apidologie 31 (3), 357-365

Francis, R.M., Nielsen, S.L., Kryger, P. (2013) Varroa-virus interaction in collapsing honey bee colonies. PLoS ONE 8 (3), e57540

Fujiyuki, T., Takeuchi, H., Ono, M., Ohka, S., Sasaki, T., Nomoto, A., Kubo, T. (2004) Novel insect picorna-like virus identified in the brains of aggressive worker honey bees. J. Virol. 78(3), 1093-1100

Iqbal, J., Mueller, U. (2007) Virus infection causes specific learning deficits in honeybee foragers. Proc. Roy. Soc. B - Biol. Sci. 274 (1617), 1517-1521

Johnson, B.R. (2010) Division of labor in honeybees: form, function, and proximate mechanisms. Behav. Ecol. Sociobiol. 64 (3), 305-316

Kralj, J., Fuchs, S. (2006) Parasitic Varroa destructor mites influence flight duration and homing ability of infested Apis mellifera foragers. Apidologie 37 (5), 577-587

Kralj, J., Brockmann, A., Fuchs, S., Tautz, J. (2007) The parasitic mite Varroa destructor affects nonassociative learning in honey bee foragers, Apis mellifera L. J. Comp. Physiol. A 193 (3), 363-370

Le Conte, Y., Mohammedi, A., Robinson, G.E. (2001) Primer effects of a brood pheromone on honeybee behavioural development. Proc. Roy. Soc. B - Biol. Sci. 268 (1463), 163-168

Le Conte, Y., Ellis, M., Ritter, W., Spivak, M. (2010) Varroa mites and honey bee health: can Varroa explain part of the colony losses? Apidologie 41 (3), 353-363

Li, Z., Chen, Y., Zhang, S., Chen, S., Li, W., Yan, L., Shi, L., Wu, L., Sohr, A., Su, S. (2013) Viral infection affects sucrose responsiveness and homing ability of forager honey bees, Apis mellifera L. PLoS ONE 8(10), e 77354 
Libersat, F., Delago, A., Gal, R. (2009) Manipulation of host behavior by parasitic insects and insect parasites. Annu. Rev. Entomol. 54, 189-207

Mallon, E.B., Brockmann, A., Schmid-Hempel, P. (2003) Immune response inhibits associative learning in insects. Proc. Roy. Soc. B - Biol. Sci. 270 (1532), 24712473

McDonnell, C.M., Alaux, C., Parrinello, H., Desvignes, J.P., Crauser, D., Durbesson, E., Beslay, D., Le Conte, Y. (2013) Ecto- and endoparasite induce similar chemical and brain neurogenomic responses in the honey bee (Apis mellifera). BMC Ecol. 13 (1), 25

Nazzi, F. (1992) Morphometric analysis of honey bees from an area of racial hybridization in northeastern Italy. Apidologie 23 (2), 89-96

Nazzi, F., Milani, N. (1994) A technique for reproduction of Varroa jacobsoni Oud. under laboratory conditions. Apidologie 25 (6), 579-584

Nazzi, F., Brown, S.P., Annoscia, D., Del Piccolo, F., Di Prisco, G., Varricchio, P., Della Vedova, G., Cattonaro, F., Caprio, E., Pennacchio, F. (2012) Synergistic parasite-pathogen interactions mediated by host immunity can drive the collapse of honeybee colonies. PLoS Pathog. 8(6), e1002735

Neumann, P., Carreck, N.L. (2010) Honey bee colony losses. J. Apic. Res. 49 (1), 1-6

Page Jr., R.E., Metcalf, R.A., Metcalf, R.L., Erickson Jr., E.H., Lampman, R.L. (1991) Extractable hydrocarbons and kin recognition in honeybee (Apis mellifera L.). J. Chem. Ecol. 17(4), 745-756

Pankiw, T., Huang, Z.-Y., Winston, M.L., Robinson, G.E. (1998) Queen mandibular gland pheromone influences worker honey bee (Apis mellifera L.) foraging ontogeny and juvenile hormone titers. J. Insect Physiol. 44 (7-8), 685-692

Poulin, R. (2010) Parasite manipulation of host behavior: an update and frequently asked questions. In: Brockmann, H.J. (ed.), Advances in the study of behavior. Elsevier Academic Press, vol. 41, pp. 151-186. Burlington, Massachusetts

Price, P.W. (1980) Evolutionary biology of parasites. Princeton University Press, Princeton

Richards, E.H., Jones, B., Bowman, A. (2011) Salivary secretions from the honeybee mite, Varroa destructor: effects on insect haemocytes and preliminary biochemical characterization. Parasitology 138(5), 602-608

Riddell, C.E., Mallon, E.B. (2006) Insect psychoneuroimmunology: immune response reduces learning in protein starved bumblebees (Bombus terrestris). Brain Behav. Immun. 20(2), 135-138

Robinson, G.E. (1987) Regulation of honey bee age polyethism by juvenile hormone. Behav. Ecol. Sociobiol. $20(5), 329-338$
Rosenkranz, P., Aumeier, P., Ziegelmann, B. (2010) Biology and control of Varroa destructor. J. Invertebr. Pathol. 103 (Suppl. 1), S96-S119

Salvy, M., Martin, C., Bagnères, A.G., Provost, E., Roux, M., Le Conte, Y., Clement, J.L. (2001) Modifications of the cuticular hydrocarbon profile of Apis mellifera worker bees in the presence of the ectoparasitic mite Varroa jacobsoni in brood cells. Parasitology 122 (2), 145-159

Sammataro, D., Gerson, U., Needham, G. (2000) Parasitic mites of honey bees: life history, implications, and impact. Annu. Rev. Entomol. 45, 519-548

Scheiner, R. (2012) Birth weight and sucrose responsiveness predict cognitive skills of honeybee foragers. Anim. Behav. 84 (2), 305-308

Schneider, P., Drescher, W. (1987) The influence of Varroa jacobsoni Oud. on weight, development of weight and hypopharyngeal glands, and longevity of Apis mellifera L. Apidologie 18(1), 101-110

Seeley, T.D. (1996) The wisdom of the hive: the social physiology of honey bee colonies. Harvard University Press, Cambridge

Shah, K.S., Evans, E.C., Pizzorno, M.C. (2009) Localization of deformed wing virus (DWV) in the brains of the honeybee, Apis mellifera Linnaeus. Virol. J. 6, 182

Thomas, F., Adamo, S., Moore, J. (2005) Parasitic manipulation: where are we and where should we go? Behav. Processes 68(3), 185-199

van Dooremalen, C., Stam, E., Gerritsen, L., Cornelissen, B., van der Steen, J., van Langevelde, F., Blacquière, T. (2013) Interactive effect of reduced pollen availability and Varroa destructor infestation limits growth and protein content of young honey bees. J. Insect Physiol. 59 (4), 487-493

Williams, G.R., Alaux, C., Costa, C., Csáki, T., Doublet, V., et al. (2013) Standard methods for maintaining adult Apis mellifera in cages under in vitro laboratory conditions. J. Apic. Res. 52 (1), 1-35

Winston, M.L. (1991) The biology of the honey bee. Harvard University Press, Cambridge

Yang, X., Cox-Foster, D.L. (2005) Impact of an ectoparasite on the immunity and pathology of an invertebrate: evidence for host immunosuppression and viral amplification. Proc. Natl. Acad. Sci. U.S.A. 102 (21), 74707475

Yang, X., Cox-Foster, D.L. (2007) Effects of parasitization by Varroa destructor on survivorship and physiological traits of Apis mellifera in correlation with viral incidence and microbial challenge. Parasitology 134 (3), 405-412

Yue, C., Genersch, E. (2005) RT-PCR analysis of Deformed wing virus in honeybees (Apis mellifera) and mites (Varroa destructor). J. Gen. Virol. 86 (12), 3419-3424 